\title{
Editorial
}

Maria Carmelita Yazbek

Doutora em Serviço Social; docente e pesquisadora do Programa de pós-graduação em Serviço Social da Pontifícia Universidade Católica de São Paulo (PUC-SP), Brasil; pesquisadora 1A do CNPq.

mcyaz@uol.com.br

\section{Raquel Raichelis}

Professora do Programa de Estudos Pós-Graduados em Serviço Social da Pontifícia Universidade Católica de São Paulo (PUC-SP), Brasil.

raichelis@uol.com.br

\section{Regina Giffoni Marsiglia}

Professora da Pontifícia Universidade Católica de São Paulo (PUC-SP), Brasil e da Faculdade de Ciências Médicas da Santa Casa de São Paulo (FCMSC-SP).

regimarsiglia@ig.com.br

\begin{abstract}
"O ser humano tem uma raiz por sua participação real numa coletividade, que conserva vivos certos tesouros do passado e certos pressentimentos do futuro. $\mathrm{O}$ desenraizamento a que nos obriga a vida moderna é uma condição desagregadora da memória. Um dos mais cruéis exercícios da opressão na sociedade moderna (opressão de natureza econômica) é a espoliação das lembranças."
\end{abstract}

Ecléa Bosi

A transição demográfica que vem acompanhando o desenvolvimento das forças produtivas nas sociedades capitalistas, se de um lado demonstra um avanço positivo nas relações homem versus natureza, do ponto de vista das relações sociais o processo deve ser analisado com mais cuidado, dada sua complexidade. $\mathrm{O}$ aumento da esperança de vida, o controle relativo da

1. Memória: enraizar-se é um direito fundamental do ser humano. Entrevista de Ecléa Bosi a Mozahir Salomão Bruck. Disponível em: <http://periodicos.pucminas.br/index.php/dispositiva/article/view/4301/4454>. Acesso em: 15 mar. 2016. 
morbidade e mortalidade precoces por doenças e carências infectocontagiosas representam avanços importantes (Campos et al., 2012).

Mas o envelhecimento de contingentes importantes da população em muitos países apresenta outros desafios que devem ser enfrentados: o aumento das doenças não transmissíveis, o empobrecimento dos trabalhadores que são afastados do mercado de trabalho e de suas famílias, a vulnerabilidade e dependência que frequentemente acompanha o envelhecimento, a segregação social, as dificuldades de desenvolvimento de novas sociabilidades e inserção em seu meio social, as mudanças nas funções, composição e dinâmica no interior das famílias que não têm como oferecer suporte a seus idosos, o limite das repostas ou mesmo a ausência delas, da parte do Estado, através de políticas de proteção social restritivas, especialmente nas formações sociais periféricas dentro do sistema.

Três artigos e um relato de experiência discutem neste número 126 da revista Serviço Social \& Sociedade questões ligadas ao envelhecimento da população, partindo de diferentes ângulos e concentrando seu olhar e análise em distintos aspectos da problemática.

O primeiro apresenta reflexões sobre a formação dos sistemas de proteção e segurança sociais destinados aos idosos, a partir do diálogo com as realidades brasileira, latino-americana e portuguesa, tomando por base a análise de produções bibliográficas sobre esta temática e a consulta à agenda pública estatal. No Brasil, em que pese a farta legislação infraconstitucional de proteção social à velhice a partir da Constituição Federal de 1988, as profundas desigualdades sociais existentes neste país de dimensão continental condicionam diferentes e heterogêneas formas de envelhecer. Aspectos culturais, sociais, econômicos e políticos determinam em grande medida o acesso a bens e serviços sociais, revelando uma situação de exclusão de grande parte da população idosa dos bens essenciais à existência humana. As propostas e análises apresentadas pelas Conferências Regionais Intergovernamentais sobre Envelhecimento na América Latina e Caribe nos anos mais recentes de 2003, 2007 e 2012 reafirmam os compromissos dos governantes dos países da região, tendo em vista a "concretização de uma sociedade para 
todas as idades". A autora aponta os diferentes graus de institucionalização das políticas sociais nesses países, mas ao mesmo tempo adverte para a grande distância de medidas e ações concretas para a sua efetivação. Já em Portugal, diferentes autores avaliam como fraco o desempenho do atual sistema de segurança social, que não assegura aos idosos "uma qualidade de vida minimamente digna”, situação agravada pela recessão econômica e pelas políticas de austeridade que põem em xeque a sustentabilidade financeira do Estado e a manutenção do sistema de segurança social.

Outro artigo sobre envelhecimento também concentra sua atenção nas políticas de proteção social na velhice que vieram se expandindo em "sociedades semiperiféricas como a portuguesa" (Lopes, 2000), tendo como marco a democratização e a modernização do país a partir da Revolução de Abril de 1974. Processo que ocorreu quando já se constatava uma dinâmica de "desaceleração das intervenções sociais públicas implementadas após a Segunda Guerra Mundial nos outros países europeus”. Analisa também de que forma nesse período foram expandidas as entidades da rede solidária, integrada por instituições de natureza associativa ou fundações "que se beneficiam de isenções fiscais e outros apoios financeiros, quando registradas como Instituições Particulares de Solidariedade Social (IPSS)”.

O terceiro artigo sobre envelhecimento trata das transformações nas relações entre sabedoria e velhice, evidenciando que os laços que remetiam a sabedoria à velhice foram se desfazendo na medida em que o capitalismo foi se desenvolvendo. $\mathrm{O}$ autor aponta o paradoxo de o intenso desenvolvimento do conhecimento científico e tecnológico de nossos tempos propiciar maior longevidade às pessoas nas sociedades contemporâneas, mas ao mesmo tempo não garantir um bom viver aos seus idosos, razão pela qual a análise busca estabelecer relações e mediações entre a ampliação das relações capitalistas e o aumento da taxa de suicídios entre idosos, principalmente nos países desenvolvidos.

$\mathrm{O}$ relato de experiência apresenta reflexões no âmbito do projeto de extensão "Universidade Aberta à Terceira Idade", desenvolvido na Universidade Federal de São Paulo — câmpus Baixada Santista. O autor recorre a 
depoimentos de idosos quando de sua interação com os meios mais antigos e mais modernos de comunicação: aparelho celular, computador, TV, cinema e rádio. Tem como base as concepções sobre as potencialidades da terceira idade, a memória dos idosos e a "educomunicação como linguagem e estratégia de conversação”. O exercício de busca da memória coletiva permitiu a recuperação parcial do passado para reflexão dos estudantes envolvidos, bem como a necessidade de se aprofundar estudos sobre a apropriação social da tecnologia, evitando-se assim processos de exclusão "principalmente em relação aos mais velhos".

O tema do cuidado que comparece neste número, embora também remetido ao envelhecimento da população, articula-se com outras questões relacionadas a grupos populacionais que vivem situações de vulnerabilidade, como doença mental, deficiência física ou mental, ou qualquer situação que leve à perda de autonomia. Abordando as intersecções entre cuidado, trabalho e sociabilidade, a autora parte da perspectiva do cuidado (care) como resultado da coexistência ontológica entre trabalho e relações sociais. Observa que as transformações do trabalho na sociedade contemporânea impactam no cotidiano, especialmente sobre as mulheres que efetuam o trabalho do cuidado. Aborda de maneira instigante o processo de mercantilização e profissionalização do cuidado, particularizando esses processos na política de saúde mental no Brasil.

De distintas maneiras, esse conjunto de artigos remete à reflexão sobre o aprofundamento do processo de expropriação do tempo do trabalho pelo capital como marca da contemporaneidade capitalista. Na sociedade brasileira, sob a égide da flexibilização neoliberal, assiste-se simultaneamente ao descarte no mercado de trabalho dos trabalhadores mais velhos e mais jovens. No caso dos idosos, não é apenas descarte de sua força de trabalho, dos direitos à proteção social de quem contribuiu por toda uma vida para gerar riqueza social apropriada privadamente, em especial no caso dos idosos da classe trabalhadora, mas também do saber acumulado, da experiência vivida, individual e coletiva, da memória, provocando o desenraizamento e a espoliação das lembranças. 
Este número da revista apresenta ainda dois artigos que tratam do fundo público e do endividamento crescente da classe trabalhadora, análises que remetem ao processo de financeirização do capitalismo em escala mundial como expressão contemporânea da racionalidade imanente do movimento do capital que busca romper as travas que impedem sua livre circulação.

Nos termos de Iamamoto (2007, p. 107): “O capital financeiro assume o comando do processo de acumulação e, mediante inéditos processos sociais, envolve a economia e a sociedade, a política e a cultura, vincando profundamente as formas de sociabilidade e o jogo de forças sociais". Trata-se de um processo que desencadeia profundas transformações não apenas nos sistemas produtivos, mas em todas as dimensões da vida social (Raichelis, 2013).

Um dos textos analisa como o capitalismo conduzido pelas finanças induz a ampliação de "produtos financeiros" agora também para amplos segmentos da classe trabalhadora assalariada, inclusive de modo inédito para as frações de menor renda, como estratégia para fazer frente à queda da taxa de lucros do capital. O núcleo duro dessa estratégia é a busca sistemática e por diferentes meios da diminuição dos custos da força de trabalho para o capital.

Vários autores (Iamamoto, 2007; Marques e Nakatani, 2013), tendo como base a teoria marxiana do valor trabalho, vêm chamando a atenção para a aparência de um fenômeno que parece ter uma lógica própria encerrada no mundo das finanças e em si mesmo, como se dinheiro gerasse mais dinheiro sem a mediação do trabalho e do processo de produção e da criação do valor como fruto da exploração do trabalho.

Para a autora, tal movimento não se desenvolve fora da dinâmica da luta de classes nem da intervenção ativa e deliberada do Estado. O papel das políticas governamentais nos campos monetário e financeiro é essencial para garantir a liberdade dos fluxos do capital sem controle, transferindo salários e lucros oriundos do trabalho produtivo para a especulação financeira, provocando a banalização do humano e a invisibilidade do trabalho e dos su- 
jeitos que o realizam, "subordinando a sociabilidade humana às coisas: ao capital dinheiro e ao capital mercadoria, potenciando, simultaneamente, as contradições de toda ordem e as necessidades sociais radicais" (Iamamoto, 2007, p. 37)

Assim é que a intervenção do Estado, por meio do fundo público, é imprescindível na administração dos ciclos de crise do capital para garantir o financiamento da acumulação e as altas taxas de extração da mais-valia e de lucratividade do capital na relação de exploração do trabalho assalariado.

Considerando que o capital financeiro avança sobre o fundo público, o Estado é chamado a intervir na disputa que se estabelece pela sua apropriação tanto pelos interesses do capital quanto do trabalho, e na própria gestão da mercadoria força de trabalho em seu processo de reprodução social a serviço da acumulação capitalista.

Se na lógica do capital a força de trabalho representa um custo excessivo, a intervenção estatal em termos de políticas econômicas e sociais se encarrega de minimizar esse custo para os proprietários do capital. Flexibilização de contratos e de direitos trabalhistas, novos modelos de gestão e controle da força de trabalho, intensificação e precarização do trabalho configuram-se no tempo presente como estratégias de ampliação da extração do capital excedente e barateamento do custo da força de trabalho.

Como se trata de um processo social conduzido pela dinâmica da luta de classes, no contexto atual do capitalismo mundializado e financeirizado as políticas estatais funcionam como poderosas estratégias de enfrentamento da crise a favor dos interesses capitalistas em jogo.

É nesse cenário que situamos os artigos que tratam do fundo público e do endividamento da classe trabalhadora nessa quadra de desenvolvimento do capitalismo monopolista no Brasil. Os autores trazem para o centro do debate a reflexão sobre a dinâmica da acumulação capitalista, a estrutura do fundo público e sua relação com as políticas sociais, questão de fundamental interesse para o trabalho profissional, considerando que as novas manifestações da questão social e seu agravamento são indissociáveis desse contexto. 
O artigo sobre o fundo público aborda temática relevante a respeito das relações entre fundo público e políticas sociais no capitalismo, particularizando o capitalismo monopolista nos países dependentes. Analisa teoricamente a dinâmica da acumulação capitalista e a estrutura do fundo público a partir da reflexão marxiana sobre a distribuição da renda e a repartição do valor, retomando e problematizando a clássica discussão de Francisco de Oliveira sobre o antivalor e sua relação com as políticas sociais. Com base nos livros 1 e 3 de $O$ capital de Marx e nas análises de Ernest Mandel e Francisco de Oliveira, estabelece ainda instigante interlocução com autores que no âmbito do Serviço Social tratam da temática do fundo público, como Elaine Behring e Evilásio Salvador, estimulando um rico debate sobre o papel do Estado e das políticas sociais em sua relação com os processos de (super)exploração, acumulação do capital e as lutas de classe, notadamente nos países dependentes.

$\mathrm{O}$ artigo sobre endividamento aborda de forma original as propostas governamentais que a partir do primeiro governo Lula provocaram a liberalização de crédito através de vários "produtos financeiros", entre eles: o cartão de crédito, de acesso restrito às camadas de renda mais alta até a década de 1980 e a partir da segunda metade dos anos 2000 amplamente ofertado aos segmentos de renda mais baixa, correspondendo à maior parcela de endividados; crédito consignado, que facilitou a cessão de créditos para funcionários públicos, aposentados e pensionistas; crédito imobiliário, priorizando as camadas de rendimentos mais baixos, principalmente para o programa Minha Casa, Minha Vida após 2009; além de crédito para compra de automóveis, facilitados com a expansão da produção do setor automotivo.

O texto chama a atenção para o alto nível de endividamento das camadas mais empobrecidas da classe trabalhadora, submetidas ao "capitalismo manipulatório" que estimula o consumismo supérfluo e desenfreado, citando várias pesquisas que apontam índices de inadimplência no Brasil maiores do que em muitos países capitalistas centrais, o que vem ensejando a disse- 
minação da "ideologia da educação financeira" em um contexto de aumento do desemprego e aprofundamento da recessão econômica.

Além disso, o estímulo ao crédito consignado atinge especialmente os aposentados e pensionistas, portanto os idosos que, apesar de possuírem uma renda segura, seus valores em média situam-se em patamares muito baixos, na grande maioria até um salário mínimo.

$\mathrm{Na}$ difícil conjuntura global, que os artigos que compõem este número evidenciam, vivemos tempo de perdas e de mudanças, não apenas em relação à ordem econômica, mas também no âmbito de nossas referências políticas, culturais e simbólicas. Revitaliza-se o pensamento conservador e emergem nova sociabilidade e nova política que "vem provocando metamorfoses no campo da subjetividade, expressas no individualismo competitivo exacerbado e pressionado pelo consumo. Fragmentam-se as diferentes esferas da vida social, e referências culturais e simbólicas que tornavam o mundo reconhecível são colocadas em questão" (Yazbek, 2012, p. 3-4)

Como lembra Barroco (2015, p. 624), a "reprodução ideológica do ideário conservador supõe sua inserção num processo histórico movido por um conjunto de determinações estruturais e conjunturais, por fatores socioeconômicos, políticos e culturais e pela dinâmica da luta de classes". Processo que nos coloca o desafio de desvendar as bases fundantes do conservadorismo moderno, questão enfrentada pelo artigo que realiza uma análise crítica das bases do conservadorismo de Edmund Burke. Se apenas em 1830 o conservadorismo começa a fazer parte do discurso político europeu, seu conteúdo já pode ser encontrado em 1790 com Edmund Burke em suas reflexões sobre a revolução na França. Nesse trabalho, o autor aborda os temas essenciais do conservadorismo, apresentando a defesa e a afirmação clara da relevância do feudalismo e de outras estruturas históricas, como a família patriarcal, a comunidade local, a Igreja, as associações e a região. $\mathrm{O}$ artigo procura recuperar o conteúdo das ideias políticas e das análises de Burke sobre o processo revolucionário na França através de uma revisão bibliográfica, destacando as principais posições do fundador do 
conservadorismo. Seu pensamento tinha forte tendência tradicionalista, combatia o Iluminismo e vai influenciar o pensamento sociológico através de conceitos como rito, status, símbolos e outros.

Outro artigo que compõe este número da revista traz ao debate uma instigante polêmica sobre o Estado-providência e sua maquinaria para produzir o que os autores denominam de um "servilismo cidadão". O texto, partindo da análise do livro de François Ewald, L'État Providence, que completa trinta anos de publicação, desenvolve uma reflexão dessa experiência histórica buscando desvendar seus mecanismos e sua operacionalização em um longo processo de assujeitamento da vida dos indivíduos. Repensar essa experiência suprimida pela política neoliberal significa questioná-la internamente. Mais do que isso, afirmam os autores que releram esse livro, "é conhecer a fina maquinaria de produção do servilismo da cidadania, esse entorpecimento ofertado como se fosse o fim da nossa sociabilidade e, ao mesmo tempo, seu processo contínuo na construção de um elemento igualmente palatável ao neoliberalismo, qual seja, o risco social”. A reflexão desenvolvida busca entender os mecanismos dessa modalidade de Estado destacando o risco como "categoria-base das políticas de solidariedade", e inaugurando uma nova forma de gestão da vida social que cria novos tipos de assujeitamento.

Finaliza este número da revista Serviço Social \& Sociedade merecida homenagem à professora Anita Aline de Albuquerque Costa, da Universidade Federal de Pernambuco (UFPE), falecida no último 5 de janeiro, um dia antes de completar seus 85 anos. Fazemos assim a viagem de volta ao início deste Editorial, registrando a participação real de Anita Aline na coletividade do Serviço Social e da UFPE, evocando a memória coletiva de uma professora que dedicou sua vida profissional ao ensino e à pesquisa na área do Serviço Social, exercendo funções acadêmicas e administrativas de natureza diversa, entre as quais se destacaram a coordenação do mestrado em Serviço Social e a direção do Centro de Ciências Sociais Aplicadas na UFPE, contribuições inestimáveis ao desenvolvimento acadêmico do Serviço Social e da universidade. 


\section{Referências bibliográficas}

BARROCO, Maria Lúcia. Não passarão! Ofensiva neoconservadora e Serviço Social. Serviço Social \& Sociedade, São Paulo, n. 124, 2015.

CAMPOS, G. W. de S. et al. Tratado de Saúde Coletiva. 2. ed. revista e ampliada. São Paulo: Hucitec, 2012.

IAMAMOTO, Marilda V. Serviço Social em tempo de capital fetiche: capital financeiro, trabalho e questão social. São Paulo: Cortez, 2007.

LOPES, A. Organizações não governamentais, políticas sociais e desenvolvimento organizacional: Welfare mixes em Portugal no domínio da luta contra a VIH/SIDA. Sociologia, Porto, v. I, n. 10, p. 131-172, 2000.

MARQUES, Rosa Maria; NAKATANI, Paulo. Crise, capital fictício e afluxo de capitais estrangeiros no Brasil. Cadernos de Recursos Humanos, Salvador, v. 26, n. 67, jan./abr. 2013.

RAICHELIS, Raquel. Proteção social e trabalho do assistente social: tendências e disputas na conjuntura de crise mundial. Serviço Social \& Sociedade. São Paulo, n. 116, 2013.

YAZBEK, Maria Carmelita. Política social e desenvolvimento: o novo padrão da dependência na América Latina e seus impactos na estrutura da desigualdade. Apresentação em mesa no XIII Enpess, Juiz de Fora, 2012. 